\title{
A LINGUAGEM DA HISTÓRIA: ENTRE O PASSADO, A FICÇÃO E AQUELE QUE ESCREVE
}

The language of History: between the past, fiction and the one who writes

\author{
Anne Caroline da Rocha de Moraes \\ https://orcid.org/0000-0003-4041-9423 \\ Universidade Federal do Paraná, Programa de Pós-Graduação em História, Curitiba, PR, \\ Brasil.80.060-150-cpghis@ufpr.br
}

Resumo: Quando ouvimos a frase "conte-me uma história", em português, pode-se estar falando dos mitos e contos de fadas, da história de vida de alguém ou dos acontecimentos da história mundial. Assim, disciplina histórica, literatura e biografia estão relacionadas quando colocamos a palavra "História" em jogo. Esse ensaio tem como objetivo pensar a relação que se estabelece entre a Literatura e a História, num debate a respeito do papel da ficção e do sujeito historiador na produção do conhecimento histórico. Para isso, mobilizamos uma bibliografia interdisciplinar, onde alguns historiadores dialogam com escritos dos filósofos Jacques Rancière e Giorgio Agamben, com o mitólogo Furio Jesi e com a psicanálise. Por fim, o texto é permeado pela grande contribuição do poeta e vidente Hermann Hesse que em seus livros de literatura pode trazer profundas reflexões não só para se pensar o sujeito, mas também para o campo da teoria e escrita da história.

Palavras-chave: Teoria da História. História e literatura. Escrita da história. Hermann Hesse.

Abstract: Upon hearing the sentence "tell me a story" in Portuguese, it may refer to myths and fairytales, to one's life story, or to World History events. Therefore, the subject History, literature and biographies are related when we put the word "Story"/"History" into play. This essay aims to think about the relationship established between Literature and History, in a debate regarding the role of fiction and the historian in the production of historical knowledge. To achieve this we mobilized an interdisciplinary bibliography, where historians have a dialogue with writings from philosophers Jacques Rancière and Giorgio Agamben, with the mythologist Furio Jesi and with psychanalysis. Lastly, the text is permeated by the great contribution from the poet and seer Hermann Hesse who in his literature books brought dep reflections both to the study of the subject as well as to the fields of History theory and writing. Keywords: History theory. History and literature. Historiography. Herman Hesse.

\section{O testemunho e o esquecido que move}

A história durante muito tempo tentou subtrair-se da literatura para marcar seu lugar sob o sol da verdade científica. Fez isso através do uso de tempos verbais específicos, de afirmações, pontos e vírgulas, tudo em seu devido lugar. E por estar entre a ciência e a literatura, sem querer, 
denunciou no seu fazer-se a incrível capacidade da linguagem de definir o que é verdade e o que é ficção. Na polida crítica que o filósofo Jacques Rancière faz a história dos Annales, ele aponta como, ao utilizar verbos no presente e no futuro, o historiador Fernand Braudel quis assegurar a primazia das coisas sobre as palavras. Ele quis se inscrever no passado como um narrador onipresente, a fim de transmitir a veracidade do acontecimento. Mas como afirma o filósofo: "existe história precisamente porque nenhum legislador primitivo pôs as palavras em harmonia com as coisas" (RANCIÈRE, 2014, p. 54).

Hermann Hesse (1970), em Viagem ao Oriente relata uma extraordinária aventura vivida por seu personagem H.H., que necessita rememorar os melhores dias de sua vida na Confraria. O autor/personagem inicia o livro evidenciando a dificuldade de se lembrar do que ocorreu, mas da necessidade de escrevê-lo. Depois de relatar questões cotidianas, festas, rituais, falar de sua relação com outros membros, fala sobre Leo - um serviçal que abandonou a Confraria no meio da jornada. A partir deste acontecimento, segundo H.H., tudo se complicou. A complicação se estendeu para além da experiência vivida, do abandono de Leo; o autor/personagem encontra-se impossibilitado de continuar a escrever sua narrativa:

Nossa Viagem ao Oriente e a Confraria, a base de nossa comunidade, foram o fato mais importante de minha vida, em vista das quais minha própria vida pessoal parecia inteiramente sem importância. E agora, que desejo rememorálas e descrever este fato tão importante, ou pelo menos parte dele, resta-me apenas um conjunto de imagens isoladas e fragmentadas que se refletem em mim, e esta reflexão, ou seja, eu mesmo, este espelho, sempre que nele me fito, nada mais é que a superfície de um vidro plano. Coloco de lado a pena com a sincera intenção e esperança de continuar amanhã ou em qualquer outro dia, ou mesmo de recomeçar uma nova narrativa, mas no fundo de minhas intenções, de minha necessidade premente de relatar nossa história, existe uma dúvida terrível. Esta mesma dúvida assolou-me durante as buscas a Leo, no Vale do Morbio. Não se limita a indagar, 'Sua história poderá ser contada?' Mas insiste na pergunta, 'Você realmente a experimentou?' Conhecemos exemplos de homens que participaram da Grande Guerra e, embora tivessem muitas histórias e fatos verídicos para contar, devem ter abrigado as mesmas dúvidas (HESSE, 1970, p. 42).

O que Hesse (1970) nos faz experimentar neste livro é a dificuldade de se testemunhar um acontecimento. A narrativa literária o deixa livre para brincar com essa dificuldade. O livro que pretendia relatar uma viagem ao Oriente, acaba descrevendo o encontro de H.H. com seu self (Hesse tinha profunda simpatia pela psicanálise junguiana), e a narrativa deixa de ser referente ao passado - a viagem que passou -, e será a descrição dos eventos aqui/agora da vida do personagem/autor. Ao falar do presente, H.H. novamente se oculta sob a escrita, e a narrativa prossegue nos moldes clássicos.

Não estaria o historiador sempre neste dilema? Assim como H.H., os historiadores partem (em sua maioria) da dificuldade primordial de não possuir lembranças - e sim testemunhas silenciosas - sobre o passado que estuda. Tem dificuldades de narrar, pois a necessidade de relatar a história tem relação com os problemas não ditos do sujeito que está no mundo - e se faz autor no momento da escrita. O personagem H.H. não só se coloca na narrativa, demonstra 
que toda narrativa é escrita por alguém que possui seus próprios dilemas, mostrando uma possibilidade à escrita do próprio historiador. Ele também mostra que mesmo a testemunha do acontecimento está impossibilitada de dar um relato consistente sobre o ocorrido.

Mas não é porque não nos lembramos, ou porque não está escrito na história, que o passado não existiu e não interfere no presente. "Só há história porque houve passado e uma paixão específica pelo passado" (RANCIÈRE, 2014, p. 96), mas ao mesmo tempo a história depende de uma dupla ausência do passado em si, que já passou e não está mais lá - e o passado que nunca esteve lá tal como foi dito - como aponta o personagem de Hesse: "Você realmente o experimentou?" (HESSE, 1970, p. 42).

$\mathrm{Na}$ descontextualizada frase de Lacan - "o que não cessa de não se escrever" (LACAN, 1985, p. 127) - enxergamos a possibilidade de fazer história. Somente porque há esquecimento é que há possibilidade da linguagem. Borges (2001), em Funes, o memorioso nos faz lembrar que a língua é representação, e exatamente por isso, aquele que não esquece não pode representar. Como conta:

[aborrecia Funes] que o cão das três e catorze (visto de perfil) tivesse o mesmo nome que o cão das três e quarto (visto de frente) [...] tinha aprendido sem esforço o inglês, francês, o português, o latim. Suspeito, entretanto, que não era capaz de pensar. Pensar é esquecer diferenças, é generalizar, abstrair. No abarrotado mundo de Funes não havia se não pormenores, quase imediatos" (BORGES, 2001, p. 128).

Mas ao contrário do personagem de Borges (2001), todos nós vivemos porque esquecemos. Por isso viver é inerente a não saber o que é a vida, e falar implica em não saber o que se diz. A esse não-saber chamamos inconsciente, este que é a reunião de tudo que esquecemos, mas que não deixa de interferir no nosso presente. Para Rancière "inconsciente e morte são duas noções equivalentes, substituíveis uma pela outra. Estar morto é não saber, é estar à espera do saber libertador sobre si mesmo" (RANCIÈRE, 2014, p. 95). Deste modo, o passado se coloca como um paciente na análise, que mostrará o oculto em seus atos falhos, sintomas, dizeres, entrelinhas; ao historiador cabe o papel de psicanalista, aquele que exatamente por ser outro trará à tona o saber sobre aquele tempo, dirá o que se diria, se fosse possível ter a consciência em seu próprio tempo. Por isso, a narrativa inventada pelo historiador não deve se basear no simples deleite pelo ofício, ele tem a função social de libertar os mortos deste não-saber, ao mesmo tempo dar esperança aos contemporâneos, de que um dia a vida que se viveu encontrará seu sentido.

\section{Juntos para sempre, o objeto e o observador}

Há outro problema que se coloca aos historiadores, mas não só a eles. Um número infindável de modelos que nos torna o que somos; modelos que parecem deixar de ser representações e parecem reais. O que nos esquecemos é que eles ainda são representações, e nós ainda estamos representando toda vez que usamos a linguagem. Afinal, como lida o historiador com o fato de que o documento não tem voz própria, não mostra uma visão total, 
não é a verdade nem a realidade?

A história é um conhecimento que não possui objeto. $O$ passado não é; a não ser pela mediação de nossa imaginação, e é também, um modelo muito bem construído como real. Ao pensarmos no passado temos no imaginário comum a ideia de que ele está disposto numa linha cronológica na qual estamos no meio - no presente - entre passado e futuro. Ideia tão arraigada que se tornou tão automática quanto imaginarmos o mundo, que é redondo, como uma simples tábula. Mas até que ponto o mapa não suplantou o mundo? Ainda hoje achamos "que o mapa seja a cópia da Terra sem perceber que é realmente o contrário: é a Terra que desde o início assumiu, para nossa cultura, a forma e a natureza de um mapa" (FARINELLI, 2012, p. 137). Ao fazermos o mapa, que é a historiografia, achamos que estamos simplesmente "copiando" a realidade do mundo, quando de fato estamos engessando um modelo sob um signo de verdade, e orientando o modo pelo qual todos deveriam vê-lo. O historiador está fadado a criar uma narrativa do passado toda vez que se depara com sua documentação; o passado não pode ser alcançado, atingido ou experimentado, ele é um objeto a ser circundado cientificamente pelos historiadores, e ficcionalmente pelos literatos, desenhistas, dramaturgos, etc.

Mas isso não significa deixar de lado a história a fim de procurar um conhecimento com mais certezas, ou que possua pelo menos um objeto palpável. Como já afirmou o historiador Michel de Certeau:

não é surpreendente que esteja em jogo, aqui, algo diferente do destino ou das possibilidades de uma 'ciência objetiva'. Na medida em que nossa relação com a linguagem é sempre uma relação com a morte, o discurso histórico é a representação privilegiada de uma 'ciência do sujeito', e do sujeito 'tomado numa divisão constituinte' - mas com a representação das relações que um corpo social mantém com a sua linguagem (CERTEAU, 1982, p. 109).

Os discursos sobre o passado são representações deste e não podemos escapar disso, visto que toda linguagem é representação. Somos advertidos sobre o perigo do anacronismo mesmo sabendo que é exatamente nele que se funda nossa pesquisa. Nós falamos pelos outros, de suas vidas, experiências, relatamos seus testemunhos e concluímos coisas a respeito; o historiador é aquele que conta a história a respeito da experiência vivida; a narrativa não é a experiência, o historiador não a viveu, mas é seu guardião. Deste modo a história

permite a uma sociedade situar-se, dando-lhe, na linguagem, um passado, e abrindo assim um espaço próprio para o presente: 'marcar' um passado, é dar um lugar à morte, mas também redistribuir o espaço das possibilidades, determinar negativamente aquilo que está por fazer e, consequentemente, utilizar a narratividade, que enterra os mortos, como um meio de estabelecer um lugar para os vivos (CERTEAU, 1982, p. 107).

Não teremos mais a ilusão de simplesmente descrever o passado acreditando que os documentos evidenciam uma rígida verdade científica, mas podemos, reunir as pistas dos documentos com uma narrativa consciente e poética, dentro de outras possíveis. Aí se insere o autor, com as perguntas que o fizeram partir para uma jornada em busca de uma verdade 
impossível de ser encontrada. Com perguntas, em primeiro lugar, anacrônicas pois buscam no passado respostas para o presente, ao mesmo tempo que quer enxergar nesse rio de representações as possibilidades outras que somente um outro tempo e espaço pode oferecer.

$\mathrm{O}$ autor (a autora neste caso) aqui não deve ser visto como um sujeito centrado, completo ou finalizado. Ela é o cruzamento de diversos discursos e modelos dispersos ou organizados que estão disponíveis hoje, e o produto de um sujeito cindido, que se utiliza da terceira pessoa do plural como artifício narrativo. Como já disse outro filósofo:

o sujeito - assim como o autor [...] — não é algo que possa ser alcançado diretamente como uma realidade substancial presente em algum lugar; pelo contrário, ele é o que resulta do encontro e do corpo-a-corpo com os dispositivos em que foi posto - se pôs — em jogo. Isso porque também a escritura [...] é um dispositivo, e a história dos homens talvez não seja nada mais que um incessante corpo-a-corpo com os dispositivos que eles mesmos produziram — antes de qualquer outro, a linguagem (AGAMBEN, 2007, p. $56)$.

\section{Ficção e realidade: distante de onde está o historiador?}

Como o historiador pode trabalhar com fontes históricas ficcionais? Dois planos devem ser pensados: um primeiro que compreende a narrativa produzida pelo historiador como ficção, em alguma medida; e outro onde a ficção se trata do objeto que o fará reinterpretar o passado. Ao usarmos a palavra ficção percebemos que está relacionada ao seu par "oposto", que seria a realidade/verdade. Ao mesmo tempo que esta oposição nos é percebida como um saber tácito, vivenciamos cotidianamente experiências que nos mostram que essas palavras não deveriam ser usadas como pares em oposição. Comumente divide-se os textos entre ficcionais e não ficcionais. Os textos não ficcionais seriam aqueles que trazem em si uma verdade ou realidade, por exemplo, textos científicos, manuais, jornais, entre outros. Já os ficcionais não estariam preocupados com a "veracidade" dos fatos, e sim com a estética e a expressão de sentimentos, ideias, reflexões (SELIGMANN-SILVA, 2013). As histórias em quadrinhos são produções ficcionais, assim como literatura, cinema, teatro, entre outros diversos. Acessando-as não temos dúvidas em classificá-las como ficção, mas será que por serem ficção elas estão em oposição à verdade? Vejamos a tira:

Figura 1 - Calvin e Haroldo falam sobre a morte
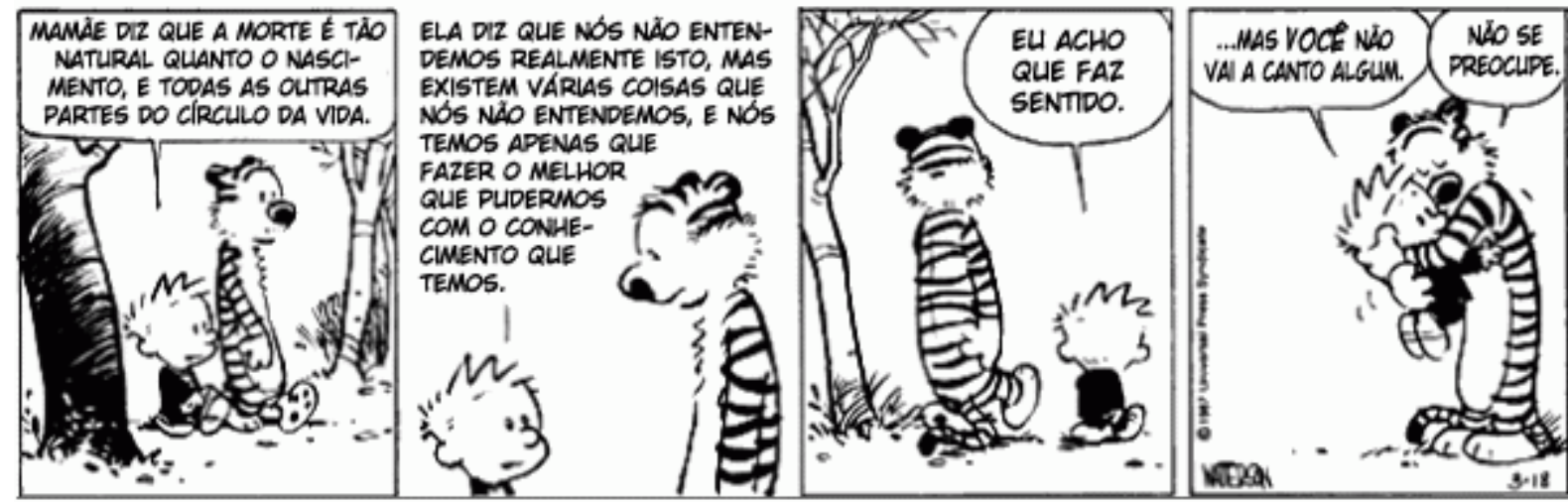
Fonte: Bill Watterson. Cavin e Haroldo conversam sobre a morte. Disponível em: http://depositodocalvin.blogspot.com/2008_10_01_archive.html. Acesso em: 31/01/2019.

Vemos acima os personagens de Bill Watterson, onde Calvin conversa com o tigre Haroldo. Já se evidencia claramente o caráter fantasioso e ficcional da história, pois se sabe ser impossível em "realidade" conversar com um tigre. Também sabemos que Haroldo é um urso de pelúcia que se transforma em tigre quando está sozinho com Calvin, e segundo o autor, o tigre é fruto da imaginação da criança. Vemos representada através de desenhos e diálogo, uma conversa na qual os personagens refletem sobre a morte. Sabendo que o quadrinho é uma ficção, não podemos dizer que ela se trata de uma mentira ou uma ilusão, pois faz o leitor compreender uma mensagem, e se relacionar com ela de modo que um produto não ficcional dificilmente faria. O que a ficção faz é movimentar o imaginário dos leitores para que o autor transmita uma ideia; e esse imaginário só pode existir baseado na experiência e percepção da vida de cada leitor.

A oposição entre fictício e real surge apenas no século XVIII, com a ascensão de um novo regime de verdade (positivista e jurídico), referenciado numa ideia de comprovação e fatos, separando as esferas entre jornalismo (factual) e romance (ficção). Mas concomitante ao surgimento da separação dessas esferas, se instaura o problema da fronteira entre fictício e factual. O resultado é o que vemos na historiografia positivista Rankeana, na qual surge a ideia de que o historiador deve combater a "contaminação da ficção" com acumulação de documentos e provas. Baseada neste pensamento, surgiu uma vasta produção historiográfica que buscava ser objetiva e isenta de opinião, e que manteve a história durante muito tempo como uma guardiã de um número restrito de nomes, datas e acontecimentos (SELIGMANNSILVA, 2013, p. 28).

A partir de meados do século XX temos uma mudança de paradigma nas Ciências Sociais, incluindo a historiografia, onde percebe-se tanto que há "real" nos textos ficcionais, quanto há ficção nos textos que se propõem factuais. Como afirma Wolfgang Iser:

Há no texto ficcional muita realidade que não só deve ser identificável como realidade social, mas que também pode ser de origem sentimental e emocional. Estas realidades por certo diversas não são ficções, nem tampouco se transformam em tais pelo fato de entrarem na apresentação de textos ficcionais. Por outro lado, também é verdade que estas realidades, ao surgirem no texto ficcional, neles não se repetem pelo efeito de si mesmas (ISER, 2002, p. 958).

Pensando nestes pressupostos, podemos repensar a relação com o ficcional da seguinte maneira: substituiremos a oposição entre real e ficcional, para introduzirmos uma relação com um terceiro termo, o imaginário. O nosso imaginário está disposto de modo difuso e disforme, e o fictício o orienta para aquilo que o criador da ficção quer: "Se o texto fíccional se refere à realidade sem se esgotar nesta referência, então a repetição é um ato de fingir pelo qual aparecem finalidades que não pertencem à realidade repetida" (ISER, 2002, p. 958), ou seja, à repetição de dada realidade se acrescenta a ideia do como se; a referência baseada no real está 
mediada pelo caráter de "fingimento" de sua repetição. Assim, "se o fingir não pode ser deduzido da realidade repetida, nele então surge o imaginário que se relaciona com a realidade retomada pelo texto. Assim o ato de fingir não pode ser deduzido da realidade retomada pelo texto" (ISER, 2002, p. 958). Deste modo, a ficção orienta o imaginário para tomar a forma que o autor da ficção pretende dá-lo, na cabeça do leitor.

A realidade aqui não é compreendida como a verdade sobre o mundo; ela é a interpretação que os sujeitos fazem de suas experiências vividas. Como não vivemos em um mundo onde palavras e coisas se encontram, temos uma amplitude de significados e sentidos que uma palavra pode ter. Cada sujeito associa às palavras aprendidas sentimentos, situações, objetos que estão disponíveis no mundo (mas que não temos acesso através das palavras); cada uma dessas "coisas" são significadas de maneiras diferentes, e cada uso de determinada palavra é a atualização desta própria.

O sujeito e o objeto não estão totalmente separados, pois para cada objeto há uma relação que o sujeito criou, uma marca mental que vai acompanhar a palavra, e a cada contexto em que ela é atualizada. Sabendo que a realidade é uma impossibilidade, não porque não existe, mas porque ela é inexplicável através da palavra e reduzida por estas, sempre o que fazemos é atualizar os sentidos de determinados conceitos e palavras, e também dessa realidade impossível de ser alcançada. Aqui, a ideia de real lacaniano se torna útil:

Não por acaso na segunda metade do século XX passa-se a falar em um real lacaniano que não pode ser descrito ou capturado pela razão ou pela imaginação. Esse real é na verdade um herdeiro da noção de trauma, i.e., de uma memória que leva em si seu apagamento. Ou seja, se nas ciências, a verdade torna-se uma questão de acerto e erro, nas humanidades, a verdade é a inacessibilidade do real, que não é mais que essa transformação do conceito freudiano de trauma, como des-encontro do real (SELIGMANN-SILVA, 2013, p. 37, grifo do autor).

O real é o des-encontro do real. Falar é dar sentido ao mundo, ao real des-encontrado. A língua é o instrumento que nos torna comuns - o que há de comum em nós é a possibilidade de aprender a significar o mundo e a si pela linguagem -, e é também ela o signo máximo da tradição, pois é a história transmitida, tornando possível também a comunicação.

Por vezes essa discussão é interpretada de modo que pareça que se negue a existência do real; não é nada disso. Esse modo de pensar busca ampliar a questão, para mostrar que toda vontade de explicação do real está envolvida numa visão unilateral da experiência que o sujeito terá com o mundo e com a língua que lhe foi transmitida. Como afirma Hermann Hesse (1992), aquele que o mitólogo Furio Jesi (2014) chama de vidente:

Se não passássemos de indivíduos isolados, se cada um de nós pudesse realmente ser varrido por uma bala de fuzil, não haveria sentido algum em relatar histórias. Mas cada homem não é apenas ele mesmo; é também um ponto único, singularíssimo, sempre importante e peculiar, no qual os fenômenos do mundo se cruzam daquela forma uma só vez e nunca mais. Assim, a história de cada homem é essencial, eterna e divina, e cada homem, ao viver em alguma parte e cumprir os ditames da Natureza, é algo 
maravilhoso e digno de toda a atenção (HESSE, 1992, p. 19).

Por não sermos isolados, relatamos histórias, e exatamente por sermos singularíssimos a comunicação absoluta da experiência através das palavras não é possível.

Mas a singularidade absoluta do sujeito não recusa o fato de haver entre nós experiências comuns. Como exemplo, os moradores de uma grande cidade possuem esse fato em comum, e "comumente" diferente da experiência de moradores do campo. Neste sentido não só a cidade - mas a cor, o gênero, a classe, e assim infinitamente -, trará uma gama de questões que aproximam os sujeitos. Mas essas experiências jamais serão comuns de modo absoluto, pois cada um deles significa-as de maneira diferente; e por mais que as palavras façam parecer esse comum como algo absoluto, cada um compreenderá as palavras ditas relacionando-as com o modo que singularmente sentem aquilo que é vivido. Esse lugar que faz com que haja a experiência comum, é sempre mediado pela significação singular que o sujeito dará àquela situação. Deste modo também as palavras são singulares e comuns ao mesmo tempo. E é a partir disso que podemos compreender que todo uso da palavra é a vontade do comum, ao mesmo tempo a impossibilidade de compartilhá-lo.

Não à toa que o mitólogo Furio Jesi (2014) nos conta sobre a relação de seu mestre também mitólogo - Karl Kerényi com Hermann Hesse deste modo: “capazes de apreender e de modelar a matéria fluida das figuras mitológicas [...] para os poetas e videntes a mitologia era objeto de participação consciente e de consciência imediata" (JESI, 2014, p. 95). Hesse modela a matéria do mito de modo singular em seu romance, que utiliza o cenário da Índia de Buda para criar seu, também vidente, personagem Sidarta, que finaliza o livro exortando exatamente as impossibilidades da linguagem:

Os conhecimentos podem ser transmitidos, mas nunca a sabedoria. Podemos achá-la; podemos vivê-la; podemos consentir em que ela nos norteie; podemos fazer milagres através dela. Mas não nos é dado pronunciá-la e ensiná-la. Esse fato, já o vislumbrei às vezes na minha juventude. Foi ele que me afastou dos meus mestres. Uma percepção me veio[...] Reza ela: 'O oposto de cada verdade é igualmente verdade.' Isso significa: uma verdade só poderá ser comunicada e formulada por meio de palavras, quando for unilateral. Ora, unilateral é tudo quanto possamos apanhar pelo pensamento e exprimir pela palavra. Tudo aquilo é apenas um lado das coisas, não passa de parte, carece de totalidade, está incompleto, não tem unidade (HESSE, 1982, p. 165).

\section{O mito, a festa e o etnólogo. O passado, a história e o historiador.}

Numa interpretação dada aos textos de Furio Jesi (2015), supomos que o etnólogo jamais compreenderá o mito participando da festa ${ }^{1}$. Primeiro porque a festa é a atualização do mito

\footnotetext{
${ }^{1}$ Usar a palavra mito já é uma problemática nos termos de Jesi. Para ele não há mito e sim uma máquina mitológica que funciona independente de estar preenchida ou vazia por um mito. Existindo ou não o mito (existindo ou não um Deus, Universo, Energia ou qualquer outro nome que se dê), ainda haverá a máquina mitológica funcionando e criando narrativas mitológicas. Apesar de buscar desativar o uso da palavra mito, o próprio autor em Gastronomia mitológica, retorna o uso da palavra num gesto auto-irônico, dizendo "o rigor dura apenas uma manhã". (JESI, 2011, p. 7).
} 
(mito que não podemos saber se existe - não existe $a q u i^{2}$ ), e segundo porque o próprio etnólogo só poderia compreender o acesso ao mito se participasse da festa, mas não tendo as mesmas referências simbólicas do outro - só pode ver o outro no ato de ver, mas não ver o que o outro vê -; o único modo é compreender a si mesmo através da festa, ouvindo a música (ou o silêncio) da sua própria máquina mitológica. Conhecer o mito e participar absolutamente da festa são duas coisas que estarão para sempre vedadas ao etnólogo pois o mito não é para nós, ele vai além das palavras, ele é a coisa, e a coisa só encontra a palavra na morte - morte que quebra o mecanismo da máquina, exatamente por ser "algo e ao mesmo tempo nada" (AGAMBEN, 2015b, p. 79). O mito não existe aqui e não é para nós, o que o etnólogo pode fazer é participar da festa a seu modo e falar sobre ela, reinterpretando-a e recriando o mito ao descrevê-lo.

Assim a total capacidade de comunicar através das palavras (palavras absolutas que dizem as coisas) é como o mito, essa palavra absoluta não existe para nós ${ }^{3}$; as nossas palavras nunca podem preencher tudo, delas sempre sobram e escapam algo, e esse algo é a impossibilidade de descrevermos o real através da linguagem. O real não é para nós - é a impossível comunicação absoluta das palavras, é nosso encontro com a morte, a vivência no mito. O que podemos fazer é o que faz o etnólogo. Ele participa da festa, tenta encontrar o mito, compreender sua atualização, mas sempre que faz isso ele, em alguma medida, reinventa o mito.

O mito é a absoluta verdade histórica, "o que aconteceu”. A festa são as coisas que estavam lá "onde tudo aconteceu", que são as nossas fontes históricas. E nós, historiadores somos os etnólogos, que nos esforçamos ao máximo para participar da festa (reviver o passado através do contato com a fontes) mas o máximo que podemos fazer é falar sobre o mito que não estamos vendo. Tentando encontrar o passado... mais uma vez.

Mas ao passo que a própria festa é a atualização do mito que jamais teremos acesso, assim também são as coisas e o "passado como realmente aconteceu”, tudo isto está vedado para todos nós, para sempre. Mesmo que fossemos escolhidos pelos deuses ou por Deus, e acessássemos essa verdade, ela seria indizível. Ao nos darmos conta que nem nós nem qualquer um é o escolhido dos deuses, logo todos que existem tratam de reinventar significados para suas coisas e seu próprio passado através da linguagem, em busca de propósitos mais diversos. Assim, o reconhecimento do caráter narrativo/poético da história não nos deve fazer cessar de escrever sobre o passado; ao contrário, nos faz compreender o papel ético da profissão de historiador ou de qualquer profissão que lide com o passado. Assim, escreveremos sobre o passado com maior consciência, pois se nós não o fizermos alguém irá fazê-lo. E nosso inimigo não cessa de fazê-

\footnotetext{
${ }^{2}$ Para Jesi é infrutífero opor a dupla é/não é em relação ao mito, pois "não há fé mais exata num 'outro mundo' que não existe aqui do que a declaração que tal 'outro mundo' não existe” (JESI, 2015, p. 74, grifo do autor). Ou seja, recusar Deus ou qualquer mito, é crer em sua negação. Como saída ele se utiliza de uma brincadeira com a linguagem expressa na partícula italiana ci non-è. Na qual se mostra uma frase com vários significados: não é aqui, não é para nós, não existe aqui e/ou não existe para nós. Cf.: nota 15 do mesmo texto.

${ }^{3}$ Agamben dá um salto na interpretação de Jesi. Tanto em O Talismã de Furio Jesi, e principalmente em Sobre a impossibilidade de dizer eu, o filósofo irá defender que a máquina mitológica pode ser pensada como a própria linguagem: "Mito é o nome que Jesi dá ao motor imóvel escondido na máquina linguística, ao 'coração de pré-ser' onde o eu falante, no limite de uma zona de não conhecimento, produz incessantemente suas mitologias". (AGAMBEN, 2015a, p. 105).
} 
$1 o^{4}$

\section{Referências}

AGAMBEN, Giorgio. A Potência do pensamento: ensaios e conferências. Trad. de António Guerreiro. Belo Horizonte: Autêntica, 2015a.

AGAMBEN, Giorgio. O Talismã de Furio Jesi. Trad. de Vinícius N. Honesko. Outra Travessia, Florianópolis, n. 19. p. 77-80, 2015 b.

AGAMBEN, Giorgio. Profanações. São Paulo: Boitempo, 2007.

BENJAMIN, Walter. Magia e técnica, arte e politica: ensaios sobre literatura e história da cultura. Trad. de Sérgio Paulo Rouanet; prefácio de Jeanne Marie Gagnebin. 8. ed. São Paulo: Brasiliense, 2012. (Obras escolhidas v. 1)

BORGES, Jorge Luis. Ficções. 3. ed. São Paulo: Globo, 2001.

CERTEAU, Michel de. A escrita da história. Rio de Janeiro: Forense Universitária, 1982.

FARINELLI, Franco. A invenção da Terra. Trad. de Francisco Degani. São Paulo: Phoebus, 2012.

HESSE, Hermann. Demian. 26. ed. Rio de Janeiro: Record, 1992.

HESSE, Hermann. Viagem ao Oriente. Rio de Janeiro: Civilização Brasileira, 1970.

HESSE, Hermann. Sidarta. Rio de Janeiro: Record, 1982.

ISER, Wolfgang. Os atos de fingir ou o que é fictício no texto ficcional. In: LIMA, Luiz Costa. (Org.). Teoria da literatura e suas fontes. Rio de Janeiro: Civilização Brasileira, 2002. 2 v, p. 955-985.

JESI, Furio. Gastronomia Mitológica. Trad. de Vinicius Honesko. Sopro: panfleto políticocultural, [s.1], n. 52, p. 5-9, jun. 2011.

JESI, Furio. Leitura do Bateau ivre. Trad. de Fernando Scheibe e Vinícius N. Honesko. Outra Travessia, Florianópolis, n. 19, p. 61-76, 2015.

JESI, Furio. Mito e imagem. Boletim de pesquisa NELIC, Florianópolis, v. 14, n. 22, p. 93-96, 2014.

LACAN, Jacques. (1972-73). O Seminário, livro 20: mais, ainda. Rio de janeiro: Jorge Zahar Editora, 1985.

RANCIÈRE, Jacques. Os nomes da história: ensaio sobre poética do saber. São Paulo: Editora Unesp, 2014.

\footnotetext{
${ }^{4}$ Referência à sexta tese de Walter Benjamim sobre a história: "O dom de despertar no passado as centelhas da esperança é privilégio exclusivo do historiador convencido de que tampouco os mortos estarão em segurança se o inimigo vencer. E esse inimigo não tem cessado de vencer”. (BENJAMIN, 2012, p. 244, grifo do autor).
} 
SELIGMANN-SILVA, Márcio. Ficção e imagem, verdade e história: sobre a poética dos rastros. Dimensões, Vitória, n. 30, p. 17-51, 2013.

\section{NOTAS DE AUTORIA}

Anne Caroline da Rocha de Moraes (anne.rocha28@gmail.com) é doutoranda pelo Programa de Pós-graduação em História da Universidade Federal do Paraná, onde também cursou mestrado e graduação. É desde 2014 vinculada à linha de pesquisa Arte, Memória e Narrativa onde desenvolve estudos sobre narrativas subversivas nos quadrinhos underground e subjetividade nos movimentos de juventude.

\section{Como citar esse artigo de acordo com as normas da revista}

MORAES, Anne Caroline da Rocha. A linguagem da História: entre o passado, a fícção e aquele que escreve. Anuário de Literatura, Florianópolis, v. 24, n. 2, p. 135-145, 2019.

\section{Contribuição de autoria}

Não se aplica.

\section{Financiamento}

O presente trabalho foi realizado com apoio da Coordenação de Aperfeiçoamento de Pessoal de Nível Superior - Brasil (CAPES) - Código de Financiamento 001

\section{Consentimento de uso de imagem}

Figura 1 - Bill Watterson. Cavin e Haroldo conversam sobre a morte. Disponível em: http://depositodocalvin.blogspot.com/2008_10_01_archive.html. Acesso em: 31/01/2019.

\section{Aprovação de comitê de ética em pesquisa}

Não se aplica.

\section{Licença de uso}

Este artigo está licenciado sob a Licença Creative Commons CC-BY. Com essa licença você pode compartilhar, adaptar, criar para qualquer fim, desde que atribua a autoria da obra.

\section{Histórico}

Recebido em: 11/06/2019

Aprovado em: 28/08/2019

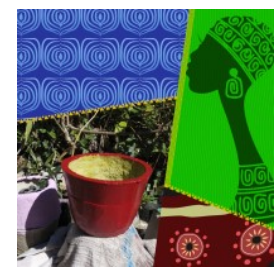

